\title{
7. Video games and the engaged citizen: On the ambiguity of digital play
}

\author{
Ingrid Hoofd
}

\begin{abstract}
This chapter questions how video games may aid civic engagement by youths. It does so by critically examining recent empirical findings on this topic, noting that such findings are often couched in a too optimistic view of the possibilities for civic engagement through games. It backs up this claim by connecting digital play with informational capitalism, proposing that this analytical connection should be complemented by foregrounding the subversive origins of play as a 'challenge' or 'duel'. The chapter ultimately suggests that play carries radical potential in terms of a transgression of oppressive social structures, but that this potential can only be tapped by pushing playful engagement beyond the logic of the cybernetic control mechanisms on which it is currently predicated.
\end{abstract}

Keywords: Serious games, civic engagement, Baudrillard, informational capitalism, cybernetics

Modern repression is carried out in the name of play.

- Baudrillard (2001, 66)

The mission to keep young people interested and engaged in a variety of forms of civic participation certainly seems to be a laudable enterprise for any self-respecting progressive and democratic society. Hard-won democratic rewards and virtues like voting, volunteering, and giving to charity, would appear to be rights and responsibilities that need to be inculcated in the young as soon as their proper socialization sets in. Especially when in the 1970 s and 1980 s it seemed that young people's participation in civic behavior

Glas, R., S. Lammes, M. de Lange, J. Raessens, and I. de Vries, eds. 2019. The Playful Citizen. Civic Engagement in a Mediatized Culture. Amsterdam: Amsterdam University Press. DOI: $10.5117 / 9789462984523 / \mathrm{CHO} 7$ 
was declining in many Western countries-leading to perhaps overwrought claims of supposed youthful political apathy (Ghosh 2011) - this led educators and politicians to start to look at alternative ways to re-engage youth to ensure the continuation of democratic institutions and behaviors and, by extension, of society. With the rise of the internet and social media, many research studies have been conducted concerning the potential benefits and shortcomings of e-democracy, online government services, and online civic engagement, and policy changes have been adopted. Indeed, a plethora of sociological studies emerged in the 1980 and 1990 around the potential of the internet for civic activism and online social movements (OSMs), as well as their impact, however limited, on real social and political change (see for instance Donk et al. 2004, as well as McCaughey and Ayers 2003). Simultaneously, the rise of video-gaming in those decades has led to a barrage of studies on serious gaming for educational purposes that range from computer-assisted chemical modeling to games that simulate ethical decision-making (Michael and Chen 2006).

This chapter will engage the question of how video games may-or especially also, may not - aide morally upright civic engagement by young people. It will do so by critically examining the empirical findings on this topic discussed in Joseph Kahne, Ellen Middaugh, and Chris Evans' landmark study The civic potential of video games (2009), arguing that the writers of this otherwise helpful study eventually adopt a too optimistic view of the possibilities of civic engagement through video games. This chapter will support this assessment by discussing literature that spells out the connection between digital play and informational capitalism, in particular building on Stephen Kline, Nick Dyer-Witheford, and Greig de Peuter's excellent study of the connections between video games and 'the military-industrial complex' in Digital play (2003). However, this chapter suggests that the latter study, however insightful, should be complemented by looking closer at the subversive origins of play as 'challenge' or 'duel' in order to analyze the potential of digital play in more depth. The chapter, in turn, suggests by way of an examination of some of the work of Jean Baudrillard that the foundation of play does carry a certain radical or subversive aspect in terms of a potential transgression of oppressive social structures and boundaries. This radical potential can however only be tapped by pushing playful engagement beyond the safety of their existence as foremost cybernetic control mechanisms; in other words, the contemporary 'civic' potential of video games lies in the ways it may exacerbate informational capitalistic risk. Hence, this chapter eventually seeks to raise the stakes of what true civic engagement, when dealt with from a politico-ethical angle that questions the relationship 
between cybernetic play and contemporary forms of gendered, raced, and classed disenfranchisement, may really entail. In order to arrive at this point, it will start off by drawing out the assumptions that emanate from the empirical research in The civic potential of video games, after which it will propose a perspective that re-theorizes the relationship between contemporary cybernetic play and civic socialization within an unequal economic landscape marked by simulation and risk.

\section{Promoting civic engagement: To what or whose ends?}

Interestingly, as Kahne, Middaugh, and Evans in The civic potential of video games point out, large-scale empirical research studies into how video games in particular may specifically aide or hinder civic engagement among the youth have been rather scarce. Moreover, most research conducted on video games and citizenry have instead speculated that playing video games simply takes time away from the exigencies of democratic citizenship or have assumed that the violent or individualistic content of video games will lead to anti-civic behavior (2009, 3). Given that a large segment of young people admits to playing video games more or less regularly, researching the ways in which gaming concretely relates to civic behavior like voting, volunteering, or helping the less fortunate, then certainly appears to make political, moral, and societal sense. In The civic potential of video games therefore, Kahne, Middaugh, and Evans set out to report on one of the first truly empirical investigations into the ways in which video games provide the grounds for potentially engaging young people in democratic processes in the United States. As they themselves confirm, their research, funded by the Chicago-based MacArthur Foundation, endeavored to collect empirical evidence for Henry Jenkins' famous claim in Confronting the challenges of participatory culture that new digital and networked tools bring about "participatory cultures" with "relatively low barriers to artistic expression and civic engagement" $(2009,5)$. In order to operationalize their research, Kahne, Middaugh, and Evans aimed at finding possible links between video-gaming and democratic behavior. They set out to collect survey data pertaining to self-reported forms of civic behavior, racial, and gender identification, as well as people's age and income bracket, together with time spent playing and the relative popularity of video games among the various groups. They also collected data about actual civic behavior and participation that the data-subjects undertook during the course of the survey. Perhaps not surprisingly, the authors conclude in their report that youth's civic 
engagement can be increased if done in a proper context-for instance, together with a classroom debate or with parental follow-up-with serious games that specifically simulate civic or moral behavior. Examples of such games are Real Lives (Educational Simulations 2001), Democracy (Positech Games 2005), Zora (Bers 2001), SimCity (Maxis 1989), and Civilization (MPS Labs 1991), and the researchers encourage parents and teachers to actively stimulate the playing of such games among teens, although they do note that the level of experienced civic engagement appears to be lower for girls than for boys $(2009,47)$. Of course, the researchers agree that the relationships between gaming and civic behavior are mere correlations; they did not for instance "control for respondents prior [civic] commitments," nor did they delve deeper into the problem around the method of self-reporting such 'civic experience' $(2009,41)$. Nonetheless, the research study appears to support the idea, however judiciously, that video games can be harnessed for inculcating democratic values into youngsters.

Besides the more obvious problems (lack of proof of causal links, biases in self-reporting) with the empirical survey method however, there are a range of other issues and assumptions that riddle this well-intended and otherwise well-conducted research project. This range of issues primarily emanates from the fact that the authors do not consider the general role of gaming technologies in the wider United States and global social environment that is shaped by a fundamentally uneven political economy. In other words, the correlations may simply stem from the equivalences between the unequal amounts of cultural capital of various socio-economic backgrounds, and levels of civic engagement in general. But more specifically, the researchers do not take into account the fact that Jenkins' astute observation about new technologies allowing for a more 'participatory' culture points toward the non-neutral emergence and imbrication of video-gaming (as well as other cybernetic technologies) in an updated form of global capitalism with its own new forms of disenfranchisement. Various scholars prefer to call this updated form 'informational capitalism' with an eye on the ways in which the apparently laudable attempt to spread digital media and media content in, for instance, schools in fact paradoxically exacerbates inequalities (Morris-Suzuki 1986; Van Dijk 2005; Fuchs 2007). Informational capitalism in turn for the most part thrives, as, for instance, Tiziana Terranova famously argues in 'Free Labor: Producing Culture for the Digital Economy,' on various forms of 'free labor' that internet users and online gamers provide, thereby facilitating an enmeshment of what seems to be leisure time with new forms of production $(2000,33)$. This imbrication of play with industry interests, as Julian Kücklich has subsequently pointed out, leads to forms 
of 'precarious playbour' in which, for instance, 'modders' provide crucial in-game innovations by putting in large amounts of pleasurable, yet unpaid time on the off-chance of perhaps getting a temporary job for a video game company (2005, n.p.). Therefore, what is lauded as 'user agency,' 'volunteering,' and 'active participation' is actually a novel type of value extraction from new media 'prosumers.' And while this, in and of itself, may arguably not be that problematic as long as these prosumers at least willingly or voluntarily give their time to provide free labor for new media companies, Kahne, Middaugh, and Evans write in a discursive register that mistakes the individual exercise of democracy, freedom, and the bringing about of actual social change with a sneaky socialization of gaming youth via new media technologies that eventually helps them comply with the workings of this uneven and immoral global capitalist order.

The problem, then, is that the harnessing of video games to boost democratic behavior may irresponsibly pre-empt the possibility to challenge the profoundly undemocratic configuration of the global information society. In other words, Kahne, Middaugh, and Evans mobilize a too-simplified and optimistic understanding of the promising connection between video games and civic society. What is therefore required beyond this empirical study, is to instead elaborate on the wider connection between video games and responsibility in order to propose another route for civic engagement proper. In order to do so, I suggest that a better understanding of the imbrication of video games and capitalism should first engage with the various deep-seated and problematic assumptions and aims that underlie such a simplified analysis like the one proposed in The civic potential of video games. Allow me, then, to elaborate how the researchers sneak such youth normalization efforts in via an arguably outdated register of democratic and civic effects emanating from what on the surface appear to be 'bottom-up' democratic gaming activities. According to the authors, the playful acquaintance with issues of political import via games simply allows young people to start caring for civic problems in a manner different from unhelpful top-down educational and parenting techniques. Youths after all, they proclaim, "prefer to talk with friends $[. .$.$] rather than with their parents" and "prefer action that$ is informal and grass-roots" (2009, 50-51). Moreover, the authors argue that "traditional instruction in a civics curriculum has frequently been cited as a major reason civics courses in general have little impact" (2009, 52). Hence, the authors propose that digital gaming allows for the dissipation of such top-down approaches to the inculcation of civic virtues among the young. By especially immersing young players into games like SimCity or Democracy that simulate civic or democratic activities, these games supposedly allow for 
creating an environment that, for instance, John Dewey claimed is crucially centered on the democratic ideals of "dialogue and active experimentation that reflects social concerns" $(2009,4)$. Seen in this light, play in general and hence digital play in particular, with its implied association to forms of improvisation and behavioral freedom, would certainly appear to have the potential of a liberatory and democratizing politics that caters to the desires and interests of its user rather than to systemically oppressive entities. New technologies that provide an essentially playful environment may therefore on the surface aide in for instance allowing citizen-users of all ages with a 'freer,' more interested and less directed engagement with their social and civic surroundings. The fact that adolescents play video games a lot is according to the authors fortuitous, since it allows for the "nurturing [of civic behavior via video games] to begin [at] a time when youths are thinking about and trying to anticipate their lives as adults" (2009, 5).

Despite the implication of a 'freer' and less directed engagement however, the authors' aim actually turns out to be quite directed indeed. The ways in which these social researchers tend to be unwittingly implicated in social and economic normalization procedures becomes apparent in how the report seeks to hide its government-managerial socialization agenda with a veneer of positive words and recommendations, as if collaborative and simulatory games can simply be harnessed in the 'right familial or educational context' for the creation of a more egalitarian United States and global society. In light of this, it is telling that their research is sponsored by the MacArthur Foundation, which in its online 'About Us' says it concerns itself with the effects of new technologies on youth in order to "improve U.S. public policy" while claiming that such studies will in fact bring about a "more just, verdant and peaceful world" (MacArthur Foundation, n.d.). The term 'verdant' (also meaning 'lush') is significant here, as its usage in this context may not only point toward the ideal of a 'greener' world, but also of a more commercially 'thriving' society. This usage therefore suggests an imbrication of this private foundation with potential commercial interests - some of which may obviously lie with those media industries who want to capitalize on the 'civic potential of gaming.' Moreover, we can notice this imbrication with commercial interests also in the argumentation for and research background of The civic potential of video games itself, as it nowhere questions the non-neutral terms and conditions of civic techniques. This can for instance be gleaned from its assumption that "raising money for charity" $(2009,5)$ is a democratizing act, even if various scholars have pointed out that financial philanthropy as a virtue only makes sense in a starkly unequal economic environment (see e.g. Gomberg 2002). It furthermore 
talks about simply teaching students "the dynamics of economic, political, and legal systems" $(2009,18)$, thereby discursively normalizing such systems. And finally, the argument for the more effective 'marketing' of games for youth ultimately betrays an at least partially commercial mindset (2009, 50). The research presented in The civic potential of video games therefore arguably has a stake in the United States' social and political economy not only via its ideological register around active participation, 'freedom,' and democracy, but also regarding the ensuring that any critique or analysis of video-gaming does not potentially hurt the United States' media industry.

But, I would argue that the general problem with studying the influences of video-gaming without regard to its imbrication in a novel political economy that primarily enriches affluent media owners in the United States and abroad, does not stop there. The real problem lies instead in the ways in which the emergence of digital play is symptomatic of the more insidious shift toward a consumer culture in which games and play, despite their basic radical potential in society, have been denigrated to become mere functional elements in this global economy. This denigration can be noticed in the subtle ways in which the authors of The civic potential of video games make problematic slippages and confusions between a gamer's or game character's actual political, economic, and social environment, and the simulation that is the video game they are playing. This slippage emerges when they, for instance, discuss the moral and political virtues of games like Halo: Combat Evolved (Bungie 2001), SimCity, and Real Lives, in which youths subsequently report that they experience collaboration, how to manage a city, and how to empathize with another youth in an impoverished country. But preprogrammed in-game experience is always fundamentally different from real-world ambiguities that cannot be computed or simplified in advance. As I have argued previously in 'The neoliberal consolidation of play and speed: Ethical issues in serious gaming' (2007) via an analysis of Real Lives and Global Warming: $\mathrm{CO}_{2} \mathrm{FX}$ (Global Warming Interactive 2010), such experiences of managerial control or empathy with the underprivileged should crucially be analyzed as simulatory experiences that first and foremost bolster the fantasy of cybernetic control while dangerously removing its user from the actual messy reality of cities and poverty. Moreover, such games dangerously obscure the extent to which global cybernetic systems of control and prediction are in fact the motor behind the aggravation of local and global inequalities, thereby leading to what I call a "double objectification"-a stereotyping on top of a distancing effect — of the other $(2007,14)$. It does not help that the The civic potential of video games authors also obscure the ways in which cybernetic technologies hide their complicity with, for instance, 
growing income gaps by arguing for the potentially leveling effects of games as "equalizing civic learning opportunities" with regards to age differences, while completely dodging the much more pernicious issue of class disparities in their report $(2009,47)$. As I conclude in 'The neoliberal consolidation' (2007), the aggravation of contemporary oppression is, paradoxically, a direct result of the well-intended and novel forms of empowerment that gaming technologies allow. This is because these gaming technologies, as accelerated cybernetic infrastructures, are at the same time tools of an intensified surveillance and disenfranchisement $(2007,13)$.

\section{Video games and the cybernetic quest to eliminate risk}

While one may argue that drawing out such complicities is beyond the scope of The civic potential of video games' explorative research, the resulting silence from the authors about the ways in which video games are thoroughly implicated in the novel form of capitalism and its various forms of inequalities along lines of gender and class, warrants a closer look at this imbrication if we really want to take their laudable call for a more democratic and egalitarian society seriously. I therefore now turn to Kline, Nick Dyer-Witheford, and De Peuter's illuminating study on this imbrication of games with the reproduction of power in Digital play: The interaction of technology, culture and marketing (2003). This book claims, following the neo-Marxist interpretation of David Harvey in The condition of postmodernity (1990), that the emergence of video-gaming exactly marks the moment of "significant 'sea change' in which capitalist societies operate" $(2003,60)$. This change has to do with the need for capitalism to constantly open up new markets in a situation in which the market of material goods started to be largely saturated from the 1960 on onwards. This, in turn, led to the emergence of new areas for consumption in the form of 'experiential commodities,' in which leisure and pleasure are sold as if they were true human needs. It is also important to note that these kinds of commodities emerged out of Cold War research and development, and therefore integrate the consumer more intimately within a cybernetic logic of command, control, communication, and information, or in military parlance: ' $\mathrm{C}_{3} \mathrm{I}$ ' $(2003,88)$. Therefore, Kline, Dyer-Witheford, and De Peuter argue that digital play in particular constitutes the exemplary consumer good of what they call 'post-Fordist/postmodern/promotional' capitalist societies and their strong ties to especially military research and development $(2003,60)$. This is because the commodification of leisure and pleasure via cybernetic 
technologies allows for the continuous involvement of the user in ongoing capitalist production across time and space, as these new commodities are ephemeral, portable, networked, and interactive, and allow for the continuous creative expression of the user's simulated identity via playful lifestyle choices. Due to the cybernetic logic and aesthetics of video games, according to Kline, Dyer-Witheford, and De Peuter, digital play tends to open up specific 'subject positions' that amount to 'masculine and militarized' positions that "mobilize fantasies of instrumental domination and annihilation" (2003, 255). This is a result of the historically intimate connection between the military and game design industries, which larger logic in certain games re-emerges in the remediation of spectacular and violent media content that we also see returning in televised news and in blockbuster Hollywood movies. Digital play as a simulation therefore crucially parallels and feeds the hyper-real simulation that is highly mediated global capitalism - in short, video games' simulated content points to the fact that it is our reality that is a very intricate simulation $(2003,69)$. Exploring this critique of digital play further, Dyer-Witheford and De Peuter in their follow-up Games of Empire assert that video games provide 'machines' that lock subjects firmly into the workings of the 'military-industrial complex' by being a particular manifestation of 'cognitive capitalism' (Dyer-Witheford and De Peuter 2009). Hypothesizing that "videogames are a paradigmatic media of Empire [...] and some of the forces that presently challenge it," (2009, xv) they finally argue that virtual gaming is "ambivalent" insofar that "game virtualities remove us from, but also prepare us for, these actual subject positions [...] simulat[ing] the normalized subjectivities of a global capitalist order" (2009, 192 and 312). Importantly, they do suggest, following the work of Gilles Deleuze and Félix Guattari, that such machinic forms of subjective control can never be total and will inevitably lead to aggravated tensions in society at large. I will return to this alternative 'potential' of games later.

Moreover, such intricate simulations have the effect of what Elizabeth Losh in 'The desert of the unreal' warningly calls "the efficiencies of learning and other forms of psychic integration" of the player into a setting geared toward military goals that may be beyond the player's purview $(2009,109)$. Following this point, as well as the general analysis in Digital play, I again argue that to have citizens engage via these digital tools with issues of national and political import-regardless of whether this is done via Halo, SimCity, or Civilization - therefore also potentially carries the implied aim of indoctrinating and implicating these users into a normalization of a more intricate and subtle capitalistic and militaristic social environment, depending on to what extent these games obscure such relations and connections. 
This environment, then, is only 'post-capitalist' insofar as the system of labor and consumption no longer relies on the alienation of the user-consumer, but in the merging of the 'prosumer' with the cybernetic feedback system that modern capitalism has become. Crucially, what then superficially appears as forms of empowerment or emancipation via these tools is paradoxically also exactly its opposite: the near-total immersion of the citizen-consumer in a web of pre-shaped 'points of cybernetic play' in which all outcomes have been predicted, pre-structured, or pre-empted as much as possible within the generalized attempt of such machinery to 'eliminate risk' (Beck 1992, 47). Understood in this way, youths' civic and moral responsibility is captured and displaced into a media network in which they can no longer truly make a difference for the United States or global society, except perhaps by fatally exacerbating the possibility of a true event.

This understanding of games as having been depreciated as normalization and indoctrination mechanisms mirrors the ways in which our society conceptually denigrates play as a mere developmental stage in children. What I claim is at issue, therefore, is finally the way in which two definitions or versions of play and games are operable in a report like The civic potential of video games as well as in the more optimistic theories around video games and the 'ludification' of culture as such. These two definitions of play are firstly, the dominant and erroneous psychological definition of play (like in children's play) as a way to experiment with and even push social rules and boundaries, and secondly, the cybernetic definition and function of play, in which play and gaming consists of the manipulation of a system of control toward its optimal performance. The problem, I contend, is that these two definitions often mesh into one another when debating the positive aspects and effects of digital play. This is because, while the former definition sees video games as a return to a childlike 'freedom' away from or in denial of the demands and responsibilities of society, the latter definition in fact creates a correspondence between the gaming subject and the objective demands of a capitalist and technocratic system that, for instance, Dyer-Witheford and De Peuter call "ludocapitalism" (2009, xiv), whereby the gamer obliquely becomes the eventual object of an insidious form of manipulation. It is for this reason, I suggest, that Jean Baudrillard's work on play and games, for instance his 'Police and play,' tends to make the point that playing games — and not just digital games, but also games as mere leisure in general - in our highly mediated society primarily consists of a "trap" of "symbolic counter-dependence which forms part of our cultural mechanisms" where "generalized repression [...] becomes part of an intense participation" (2001, 61). The pleasure of playing games, according 
to Baudrillard, stems from the artificial production of needs and desires, leading to a "complicit euphoria" when engaging in the generalized game that cybernetic society on the whole has become $(2001,61)$. In other words, Baudrillard suggests that our entire modern society consists of a capitalist seduction of the masses to engage in playing, as well as the accumulation of pleasure and experience as not only a new form of production, but also as a way to divert libidinal energy away from an actual challenge to or transgression of this seductive system. The ludification of society, then, far from being a true revolutionary or freeing transformation for the subject, instead ensures that that subject is "harmoniously integrated into the dynamics of production" by providing the illusion that play and gaming allows her or him to guiltily give in to his own childlike desires $(2001,65)$. Gaming is thus presented in the popular imaginary as a return to a freer and infantile state, whereas actually it is engaging in the highest-order demands of cybernetic capitalism. Moreover, the 'guilty pleasure' of playing games is "above all socially orchestrated like any other cultural trait of behavior or clothing," ensuring that the consumption of culpability itself allows for the misunderstanding of the mere "signs of play" as a true playing with the actual stakes of life and the social order $(2001,66)$. Actual transgression or radical social change, then, seems near-impossible, and can only be found in what he calls the "unpredictable transgressions and convulsions in the system of values." One may think here of events that seemingly have little to do with video games, like the never-explained flash crash of 2001, terrorist suicide attacks, or the ongoing increase in high-school shootings in the United States. At the same time, however, video games may have contributed to such accidental events by raising the stakes of informational capitalism in much more obscure ways, which I will address next.

\section{Play as challenge to neoliberal socialization}

After taking the important caveat by Kline, Dyer-Witheford, and De Peuter as well as the assessment by Jean Baudrillard in 'Police and play' seriously, the possibilities and impossibilities for citizen-directed liberatory and democratizing play via digital tools like video games and other forms of digital play should be understood as paradoxically oppressive because they are seemingly emancipatory. It is, namely, the very same computational and infrastructural mechanism that allows for student empowerment, which at the same time re-distributes social and economic hierarchies in exceedingly unequal ways. But here, too, is an oblique relation to be found 
between the excessive events mentioned just now and video games: the flash crash resulted from 'playing' the stock market, and the shootings simulate the simulations that are shooter games. I would therefore also suggest that a totalizing theory of capitalism as a system that can completely predict and pre-empt outcomes - and ultimately eliminate all risk-via games and play in the ways Kline and his colleagues sketch, forgets that capitalism today actually relies on extremely unstable illusions, which get illustrated via such excessive and surprising events. Therefore, I propose that one can always imagine upping the stakes via a challenge to the rules of leisure and pleasure as such; in other words, any system can be 'gamed' beyond its limits. In order to grasp this potential of video-gaming on a more extra-structural level, I propose that the seemingly pessimistic and totalizing assessment Baudrillard makes in 'Police and play' nevertheless should be complemented with his more intricate analysis of the symbolic logic of rules and games in his earlier work Seduction (1990). In this work, he seeks to comprehend 'prosumerist' seduction as the potential thwarter of the pervasive order of production, which he jokingly calls the "Great Neutral Aleatorium" $(1990,143)$. Here, too, Baudrillard argues that play today is the "ambience or playful eroticization of a universe without stakes," but that games in their original agonistic character of the 'duel' actually form a superior form of social ordering vis-à-vis a society based on the production and assuaging of supposedly essential human needs and desires (1990, 156). This is because in cultures where the gods (or any large powers) are invited - for instance, by ways of ritual sacrificial offering - to show their powers, humans actually play for real and there are potentially lethal stakes that may completely change a community, a society or the course of history. This means that societies that truly acknowledge seduction as the flip-side of production are able to 'place bets' that are truly radical in the face of the law or of authority. So, while in our modern society games are co-constitutive of a "demand [which] is prompted by the model, and the model's precession is absolute, [so that] challenges are impossible," still games and rule-based play can be seen as a remnant of a "yearning to be free of the contract and the social relation, the longing for a crueller if more fascinating destiny for exchange," in short, "a yearning for a more adventurous world, where one plays with value more recklessly" (1990, 152-157).

What I take from Baudrillard's assessment is that, even if our society is one where seduction in Baudrillard's words has become "cool" or "cold" since it no longer raises any stakes $(1990,162)$ — and therefore does nothing to really change society toward a more egalitarian or democratic state - the incessant pushing of production via the seduction of video gamers into 
leisurely 'prosumerism' nonetheless carries with it an equally increasing unpredictable or risky element. This is because 'cold' seduction via 'prosumption' is centered on the individual satisfaction of desires and pleasures that eventually appear unreal in the face of truly giving oneself away for a larger cause, whether this cause be moral, civic, democratic, or otherwise. Altruistic self-satisfaction via digital engagement is, therefore, always ultimately unfulfilling because the performance and experience of empathy or leadership is, ultimately, indeed only a simulatory illusion that will forever stand in tension with actual moral and material global effects that is in part caused by the machinery of 'cold' seduction. Moreover, it is quite possible that young people, due to their underdeveloped socialization, may at some level be more sensitive to the tensions around such 'altruism' than well-adjusted social researchers. The much-lamented youthful political and moral "disaffection" that I noted at the onset of this chapter, is hence, I suggest, best interpreted as a symptomatic effect of the "fake game without stakes" that modern living has become (Baudrillard 1990, 163). Since the acknowledgement of the power of seduction is, according to Baudrillard, historically gendered in Western societies, this may also explain why in the United States "girls experience lower civic gaming opportunities" as the authors of The civic potential of video games bewilderedly note $(2009,47)$; they may not be as easily seduced into video games' 'militarized masculinity.' After all, not only are in-game representations frequently sexist (Kline, Dyer-Witheford, and De Peuter 2003, 265), but girls are possibly more sensitive to the fact that gaming relies on an illusion that is at some level complicit with a highly gendered and patriarchal social order. This also means that games are, or at least can be, much more serious than the regular psychological definition of play as a supposed recursion to a childlike phase gives it credit for, and that it is finally on the level of the theatrical function of the media industry, which obscures that industry's imbrication in the productive and predictive function, that the real challenge to the inequalities of contemporary capitalism should be played out. Or, as Baudrillard puts it rather obliquely at the end of 'Police and play': "only subversion of an instinctual order can constitute a point external to the system" (2001, 68).

\section{Conclusion: Raising the stakes of civic subversion?}

The final question, then, becomes what might accomplish such a subversion? In light of this question, I would like to briefly discuss two promising ways in which software programmers and designers have tried to up the 
stakes in video-gaming by pointing toward a beyond of its pervasive, yet never totalizing grasp on play's potential radicalism. The first way entails introducing an explicit element of self-reflexivity in a game, such that the in-game representation no longer obscures its relation to an unequal global economy, but instead critically re-stages this relation. There are a number of interesting attempts made in this area, like for instance the games Necessary Evil (Gualeni 2013a) and You Have to Burn the Rope (Bashiri 2008), which both seek to frustrate the player's usual sense of smooth control over the game-world, or thwart the escapist disconnection with the context in which video games are played. As Stefano Gualeni, one of the makers of Necessary Evil, nonetheless admits in 'Self-reflexive video games as playable critical thought,' such games often encompass a kind of "uncouth gameplay" that might lead to an unpleasant or indifferent gaming experience, which may aim for some kind of player awareness but will not fundamentally alter the rules of the larger game that is post-Fordism (2013b, n.p.). The reach of self-reflexive video games will therefore-also seeing that it will still have to operate entirely within the contemporary economy of 'seductive prosumerism' - eventually remain limited to the uneventful stakes of contemporary informational capitalism. The second way would encompass a more serious transgression of the rules of digital communication via various forms of malicious hacking. However, while challenging the status quo via malicious hacking obviously transgresses some moral or legal boundaries, informational capitalism, with its emphasis on the constant harnessing of ephemerality and creativity via the seduction of also a player's more obscure impulses, may simply incorporate and produce such transgressive activities as part of what Stephen Flowers has called "outlaw innovation" $(2008,178)$. So, even self-reflexivity as well as hacking may ultimately not lead to the subversion of the ways in which our social order relies on the production of subversive instincts and pleasures via video games. Nonetheless, I suggest that they point in the right direction, and would urge critical social scientists and game designers to further ponder its 'uncouth' potentials. And while Kahne, Middaugh, and Evans also seek to point toward such potentials, the overall argument in The civic potential of video games nonetheless remains stuck in a moralism about proper civic behavior that does not lead to any of the necessary 'uncouthness' at all.

To sum up, this chapter has argued that much contemporary digital play - whether done via more obviously militarised games like the Halo series or more blatantly 'civic' games like Democracy — is wholly wrapped up in the logic of cybernetic prediction, oppression, and the reproduction of the inequalities of global capitalism. As such, the seduction of digital 
gaming is a 'cold' one in which there is nothing really at stake. The chapter has proposed that such a digital environment in which stakes and risks have been pre-empted at least to a larger extent than in a pre-cybernetic media environment, can never allow for true ethical engagement and radical democratic change implied on the level of certain video games' 'civic' content. Hence, the chapter concludes that, following especially Baudrillard's assessment of the ambiguity of play while also paying attention to the warnings of Kline, Dyer-Witheford, and De Peuter, eventually only play that engages on the structural, formal, or functional level of its digital tool may open up the possibility of a liberatory politics. Games like SimCity or Zora, as The civic potential of video games report claims, therefore, certainly generate a particular experience of moral and civic learning, but such an experience primarily involves the practice of playing within the general ambience of the optimization of "self-control" technologies geared toward the management of risk (Beck 1992, 234). It therefore does not translate into the nurturing of a more democratic and ethically just society, but instead socializes youths into a contemporary technocracy fraught with multiple forms of inequality. This is because the in-game spatial or social representation, while seemingly full of 'freedom' of movement and choice, only serves to hide the way in which such 'freedom' reproduces an essentially oppressive functionality within contemporary global informational capitalist society. In their place, the chapter has pointed out that certain forms of playful self-reflexivity and hacking offer promising routes to subversion that nonetheless still need to be pushed way beyond the system's breaking point so as to potentially accomplish play's essential radicality. This chapter therefore has positioned itself initially in-between, but finally beyond the debates of Kahne, Middaugh, and Evans as well as Kline, Dyer-Witheford, and De Peuter, as it holds that the former fail to sufficiently address how video games are also microcosms of larger, socially oppressive, and unequal arrangements, while the latter in Digital play forget how structural play with 'dubious' technologies is always possible on the level of the tool's rule-based grammar. It concurs with the latter that the stakes for a liberatory politics indeed have been partially compromised and complicated, as truly subversive, radical, or civically engaged play is rendered increasingly difficult to discern and carry out in our informational capitalist societies due to the near-total enmeshment of emancipatory desires and new media. But it also suggests that one can always 'up the game' and its unjust and finally arbitrary rules by exposing these rules as simulations. Dyer-Witheford and De Peuter do try to investigate the possibility of raising such stakes by looking at a variety of promising games in the chapter 'Games of multitude' in Games of Empire, like tactical 
games, polity games, hacktivism, and other forms of counterplay. Eventually, however, this investigation still leads them to conclude that the "play of multitude still remains locked inside games of Empire" (2009, 213). This is because all these games still fundamentally rely on extracting surplus value by locking users into preprogrammed interactive subject positions. Dyer-Witheford and De Peuter therefore propose that perhaps "gaming alternatives that open onto truly 'new universes of references' come mainly from outside the play factory" $(2009,212)$. I suggest that if we really want our youth to grow up with a sense of democratic purpose in which they can bring about a world in which we can all lead meaningful lives, we should perhaps understand that, paradoxically, youth's seemingly irrational and 'passive' civic behavior, borne out of a logical disaffection with zero-stakes technocracy, is not so much the problem, but the key to a more just society. This is not to say that indulging in passivity constitutes the opposite of the problems of interactivity, but that youth, as the The civic potential of video games report correctly showed at the start, find themselves on the threshold of what it really could mean to become a responsible adult. And their instincts may tell them that deep down, not all is well in the sphere of civic simulation.

\section{References}

Bashiri, K. 2008. You have to burn the rope. [browser]. Game.

Baudrillard, J. 199o. Seduction. Trans. B. Singer. New York: St. Martin's Press. —. 2001. Police and play. The uncollected Baudrillard, ed. G. Genosko, 61-69. London: Sage Publications.

Beck, U. 1992. Risk society: Towards a new modernity. London: Sage Publications.

Bers, M. 2001.Zora. [Windows]. Massachusetts Institute of Technology. Game. Bungie. 2001. Halo: Combat Evolved. [Xbox/Windows/OS X]. Microsoft Game Studios. Game.

Dyer-Witheford, N., and G. de Peuter. 2009. Games of Empire: Global capitalism and videogames. Minneapolis, MN: Minnesota University Press.

Educational Simulations. 2001. Real Lives. [Windows]. Educational Simulations. Game.

Flowers, S. 2008. Harnessing the hackers: The emergence and exploitation of Outlaw Innovation. Research Policy 37 (2): 177-193.

Fuchs, C. 2007. Internet and society: Social theory in the information age. New York: Routledge. 
Ghosh, P. 2011. Why is there so much voter apathy in U.S. elections? International Business Times, 19 September 2011. http://www.ibtimes.com/ why-there-so-much-voter-apathy-us-elections-315494.

Global Warming Interactive. 2010. $\mathrm{CO}_{2} \mathrm{FX}$. [Web]. Global Warming Interactive. Game.

Gomberg, P. 2002. The fallacy of philanthropy. Canadian Journal of Philosophy $32(1): 29-65$.

Gualeni, S. 2013a. Necessary Evil. [browser]. Game.

-. 2013b. Self-reflexive video games as playable critical thought. Gamasutra. http://www.gamasutra.com/blogs/StefanoGualeni/20131029/202847/ selfreflexive_video_games_as_playable_critical_thought.php.

Harvey, D. 1992. The condition of postmodernity: An enquiry into the origins of cultural change. New York: Wiley and Sons.

Hoofd, I. M. 2007. The neoliberal consolidation of play and speed: Ethical issues in serious gaming. Critical Literacy: Theories and Practices 1 (2): 6-15. Jenkins, H. 2009. Confronting the challenges of participatory culture: Media education for the 21st century. Cambridge, MA: The MIT Press.

Kahne, J., E. Middaugh, and C. Evans. 2009. The civic potential of video games. Cambridge, MA: The MIT Press.

Kline, S., N. Dyer-Witheford, and G. de Peuter. 2003. Digital play: The interaction of technology, culture, and marketing. Montreal: McGill-Queen's University Press.

Kücklich, J. 2005. Precarious playbour: Modders and the digital games industry. The Fibreculture Journal 5. http://five.fibreculturejournal.org/ fcj-025-precarious-playbour-modders-and-the-digital-games-industry.

Losh, E. 2009. The desert of the unreal: Democracy and military-funded videogames and simulations. In Virtualpolitik: An electronic history of government media-making in a time of war, scandal, disaster, miscommunication, and mistakes, ed. E. Josh, 97-136. Cambridge, MA: The MIT Press.

MacArthur Foundation. n.d. About us. MacArthur Foundation. http://www. macfound.org/about.

Maxis. 1989. SimCity. [multiplatform]. Maxis/Brøderbund/Infogrames. Game.

McCaughey, M., and M. D. Ayers. 2003. Cyberactivisms: Online activism in theory and practice. New York: Routledge.

Michael, D. R., and S. Chen. 2006. Serious games: Games that educate, train and inform. Boston, MA: Thomson Course Technology.

Morris-Suzuki, T. 1986. Capitalism in the computer age. New Left Review 160:81-92.

MPS Labs. 1991. Civilization. [multiplatform]. MicroProse. Game. 
Positech Games. 2005. Democracy [Windows/OS X/Linux]. Positech Games/ Tri-Synergy. Game.

Terranova, T. 2000. Free labor: Producing culture for the digital economy. Social Text 18 (2): 33-58.

Van Dijk, J. 2005. The deepening divide: Inequality in the information society. Thousand Oaks, CA: Sage Publications.

Van de Donk, W., B. Loader, P. Nixon, and D. Rucht. 2004. Cyberprotest: New media, citizens, and social movements. New York: Routledge.

\section{About the author}

Ingrid M. Hoofd is an Assistant Professor in the Department of Media and Culture at the Humanities Faculty of Utrecht University, the Netherlands. Her research interests are issues of representation, feminist and critical theories, philosophy of technology, game studies, and information ethics. She is the author of Higher education and technological acceleration: The disintegration of university teaching and research (Palgrave 2016), and Ambiguities of activism: Alter-globalism and the imperatives of speed (Routledge 2012). Her research analyzes the ways in which alter-globalist activists, as well as left-wing academics, mobilize what she calls 'speed-elitist' discourses and divisions in an attempt to overcome gendered, raced, and classed oppressions worldwide. These analyses outline the accelerated tensions and relationships between various new technologies (electronic games, e-learning platforms, and social media) and activist-academic moral imperatives from a criticalcultural and deconstructionist perspective. 
